\title{
A rapid culture independent methodology to quantitatively detect and identify common human bacterial pathogens associated with contaminated high purity water
}

\author{
Elizabeth Minogue ${ }^{1}$, Nina L Tuite ${ }^{1}$, Cindy J Smith², Kate Reddington ${ }^{1}$ and Thomas Barry ${ }^{1 *}$
}

\begin{abstract}
Background: Water and High Purity Water (HPW) distribution systems can be contaminated with human pathogenic microorganisms. This biocontamination may pose a risk to human health as HPW is commonly used in the industrial, pharmaceutical and clinical sectors. Currently, routine microbiological testing of HPW is performed using slow and labour intensive traditional microbiological based techniques. There is a need to develop a rapid culture independent methodology to quantitatively detect and identify biocontamination associated with HPW.
\end{abstract}

Results: A novel internally controlled 5-plex real-time PCR Nucleic Acid Diagnostics assay (NAD), was designed and optimised in accordance with Minimum Information for Publication of Quantitative Real-Time PCR Experiments guidelines, to rapidly detect, identify and quantify the human pathogenic bacteria Stenotrophomonas maltophilia, Burkholderia species, Pseudomonas aeruginosa and Serratia marcescens which are commonly associated with the biocontamination of water and water distribution systems. The specificity of the 5-plex assay was tested against genomic DNA isolated from a panel of 95 microorganisms with no cross reactivity observed. The analytical sensitivities of the S. maltophilia, B. cepacia, $P$. aeruginosa and the S. marcescens assays are 8.5, 5.7, 3.2 and 7.4 genome equivalents respectively.

Subsequently, an analysis of HPW supplied by a Millipore Elix 35 water purification unit performed using standard microbiological methods revealed high levels of naturally occurring microbiological contamination. Five litre water samples from this HPW delivery system were also filtered and genomic DNA was purified directly from these filters. These DNA samples were then tested using the developed multiplex real-time PCR NAD assay and despite the high background microbiological contamination observed, both S. maltophilia and Burkholderia species were quantitatively detected and identified. At both sampling points the levels of both S. maltophilia and Burkholderia species present was above the threshold of $10 \mathrm{cfu} / 100 \mathrm{ml}$ recommended by both EU and US guidelines.

Conclusions: The novel culture independent methodology described in this study allows for rapid $(<5 \mathrm{~h})$, quantitative detection and identification of these four human pathogens from biocontaminated water and HPW distribution systems. We propose that the described NAD assay and associated methodology could be applied to routine testing of water and HPW distribution systems to assure microbiological safety and high water quality standards.

Keywords: Human microbial pathogens, Multiplex real-time PCR NAD assays, Biocontaminated HPW distribution systems, Biological water quality assurance

\footnotetext{
*Correspondence: thomas.barry@nuigalway.ie

${ }^{1}$ Nucleic Acid Diagnostics Research Laboratory (NADRL), Microbiology, School

of Natural Sciences, National University of Ireland Galway, Galway, Ireland

Full list of author information is available at the end of the article
} 


\section{Background}

Maintaining high water quality standards is crucial, as water is essential to human health, development and well-being. The efficient operation and biological control of water distribution systems is important as High Purity Water (HPW), municipal and recreational water contaminated with waterborne pathogens such as nonfastidious Gram-negative bacteria non Enterobacteriaceae (GNB-NE) can pose a serious risk to human health. Water, and in particular HPW, is a vital component of both the clinical and many industrial manufacturing sectors such as the pharmaceutical, food and beverage and semiconductor industries [1-3].

In healthcare facilities, such as neonatal units, intensive care units, dental practices and clinical diagnostics testing laboratories, water and HPW is routinely used for hand washing, bathing, cleaning semi-critical areas washing and rinsing patient medical devices and in the preparation and processing of medicines and other health products $[4,5]$. A recent traditional culture based microbiological study of water and water distribution systems in a number of hospital departments revealed high levels of contamination by GNB-NE [6]. In such settings, this microbial contamination with opportunistic pathogens could result in the transmission of Healthcare Associated Infections (HCAIs) in immunocompromised patient groups [7-10]. There have been many reported cases of HCAIs associated with microbial contamination of water and HPW delivery systems and exposure to these water-borne pathogens in hospitals can result in increased patient morbidity and mortality [11-13]. It has also been observed that the use of biocontaminated water and HPW for clinical culture based microbiological diagnostics can result in the outbreak of pseudoepidemics $[14,15]$. Such clinical derived pseudoepidemics can result in costly additional and unnecessary diagnostic procedures and therapeutic interventions for patients [16-19].

In industrial settings, microbial contamination of water and HPW distribution systems can result in the biodeterioration of manufacturing equipment and as previous studies have demonstrated contamination with microorganisms can severely compromise the quality of industrial raw materials and finished products [20-22].

Previous studies have demonstrated that the microbial load present in water distribution systems can be significantly underestimated using the traditional plate count microbial culture method as a result of the presence of physiologically active bacteria that are unable to form colonies on culture media [23,24]. These viable but nonculturable bacteria may therefore be undetectable by standard microbial cultivation [25]. It has also been observed that variables such as the sampling technique and culture medium used can be crucial in obtaining accurate and reproducible results when testing these water samples
[26]. Such studies demonstrate the need for and importance of real-time monitoring for the onset of biocontamination of HPW purification units and HPW delivery systems by rapid microbial culture independent methods such that prompt remedial action may be undertaken.

Therefore, there is a need to develop rapid, sensitive and high throughput methodologies for the quantitative detection and identification of biocontamination associated with HPW to ensure appropriate standards and quality can be achieved. Nucleic Acid Diagnostics (NAD) technologies offer the potential to analyse in real-time the onset and progress of microbial biocontamination associated with HPW distribution systems. Previously, we have reported the design and development of an internally controlled multiplex real-time PCR NAD assay for both P. aeruginosa and Burkholderia species for use in the quantitative detection and identification of these GNB-NE in biocontaminated HPW under laboratory conditions [27]. For the present study, additional novel NAD targets for two more GNB-NE, S. maltophilia and S. marcescens have been incorporated resulting in a 5-plex real-time PCR NAD assay, inclusive of an Internal Amplification Control (IAC).

This study which was designed in accordance with Minimum Information for Publication of Quantitative Real-Time PCR Experiments (MIQE) guidelines [28] describes a methodology combining water filtration, DNA purification and NAD technologies to detect, identify and absolutely quantify these common human pathogenic contaminates of HPW. Furthermore, we have also demonstrated the developed methodology by testing a HPW delivery system supplied by a Millipore Elix 35 water purification unit distributing HPW based in a public building facility. The Millipore Elix 35 system uses both reverse osmosis and electrodeionization for production of HPW. Using the developed methodology, we determined that the HPW delivery system was contaminated with the human pathogens, S. maltophilia and Burkholderia species.

\section{Methods}

\section{Bacterial strains, microbial culture media and growth conditions}

Ten Stenotrophomonas species/strains, 10 Burkholderia species, 26 Pseudomonas species/strains and 10 Serratia species/strains were used in this study (Additional file 1: Table S1). All target species/strains were purchased from either the German Collection of Microorganisms and Cell Cultures (Deutsche Sammlung von Mikroorganismen und Zellkulturen GmbH, DSMZ. Braunschweig, Germany) or from BCCM Belgian Co-ordinated Collections of Microorganisms bacterial collection (LMG, Gent, Belgium) (Additional file 1: Table S1). 
All Stenotrophomonas, Burkholderia, Pseudomonas and Serratia species were grown in tryptone soya broth (Oxoid, Cambridge, UK) or R2A broth (Lab M limited, Lancashire, United Kingdom) at either $30^{\circ} \mathrm{C}$ or $37^{\circ} \mathrm{C}$ for approximately $12-24 \mathrm{~h}$ or until sufficient growth was observed. For all other microorganisms tested in the study, total genomic DNA was provided from microbial stocks held within this laboratory (Additional file 1: Table S1).

\section{DNA isolation and quantification}

Total genomic DNA was isolated from overnight broth culture using the Quick-gDNA MiniPrep kit (Zymo Research, California, USA). Briefly, $1.5 \mathrm{ml}$ of culture was centrifuged in a bench-top centrifuge at 18,000 $\mathrm{g}$ for two min. The supernatant was discarded and the pellet was resuspended in $400 \mu \mathrm{l}$ Genomic Lysis Buffer by vortexing briefly, then incubated at room temperature for 5-10 min. Subsequently, steps 2-5 of the purification of total DNA from cell suspensions and proteinase $\mathrm{K}$ digested samples procedure were followed according to the manufacturer's guidelines (http://www.zymoresearch.com/ downloads/dl/file/id/18/d3006i.pdf).

DNA integrity was assessed on a $1 \% \mathrm{w} / \mathrm{v}$ agarose gel. Concentrations for all total genomic DNA used in this study were determined using the Quant-i $\mathrm{T}^{\mathrm{TM}}$ dsDNA HS Assay Kit and the Qubit fluorometer (Invitrogen Corporation, California, USA). All DNA samples were stored at $-20^{\circ} \mathrm{C}$ prior to use.

\section{Diagnostics target identification and development}

The diagnostics target genes used in this study were identified by in silico evaluation of a number of genes currently under investigation and evaluation in this laboratory for use in nucleic acid based diagnostics test systems. These include the $s s r A, \operatorname{lep} A, \operatorname{rnp} B, 16 \mathrm{~S}$ rRNA, and genes and the 16 - $23 \mathrm{~S}$ rRNA ITS. These gene targets have all previously been reported as useful species specific diagnostics targets for use in nucleic acid based diagnostics [29-35]. Nucleotide sequence information was retrieved from the National Center for Biotechnology Information (NCBI) website (http://www.ncbi.nlm.nih.gov), the Functional Gene Pipeline and Repository website (http://fungene. cme.msu.edu), the RNaseP database (http://www.mbio. ncsu.edu/rnasep/) and the tmRNA databse (http://www. ag.auburn.edu/mirror/tmRDB/). Alignments of these nucleotide sequences were carried out using the clustalW2 multiple sequence alignment programme (http://www. ebi.ac.uk/Tools/clustalw2/index.html).

\section{Conventional and real-time PCR primers and Taqman hydrolysis probe design}

All oligonucleotide primers and hydrolysis probes were designed manually according to recommended general guidelines [28,36]. Nucleotide sequencing primers were designed to have a melting temperature (Tm) of between $60-62^{\circ} \mathrm{C}$. The oligonucleotide primers used for real-time PCR were designed to have a Tm of $58-61^{\circ} \mathrm{C}$, with all probes designed to have a $\operatorname{Tm} 6-8^{\circ} \mathrm{C}$ higher (Table 1 ). To determine the specificity of each assay designed in silico all primers and probes were BLAST analysed. Subsequently, the performance characteristics of each primer set was analysed in the laboratory along with the specific probe. The most robust assay combination, as reflected by PCR efficiency, which had an LoD of $<10$ GE was used in the final assay. Oligonucleotide primers and probes were supplied by Eurofins MWG Operon (Ebensburg, Germany), TIB MOLBIOL (Berlin, Germany) or Integrated DNA Technology (Leuven, Belgium).

\section{Conventional PCR for sequencing}

Conventional PCR was performed on the iCycler iQ thermal cycler (Bio-Rad Laboratories Inc., California, USA). PCR reactions were carried out in $0.2 \mathrm{ml}$ PCR tubes, containing forward and reverse primer $(0.2 \mu \mathrm{M}$ final conc.), $2.5 \mu \mathrm{l} 10 \mathrm{X}$ buffer $\left(15 \mathrm{mM} \mathrm{MgCl}_{2}\right), 0.5 \mu \mathrm{l}$ dNTP mix (10 mM: deoxynucleoside triphosphate set, 0.5 U Taq DNA polymerase Roche Diagnostics, Basel, Switzerland), $1 \mu$ l of template DNA and adjusted to a final volume of $25 \mu \mathrm{l}$ with the addition of nuclease-free water (Applied Biosystems, California, USA). The thermal cycling parameters consisted of an initial denaturation step at $95^{\circ} \mathrm{C}$ for $4 \mathrm{~min}$, followed by 35 cycles of denaturation at $95^{\circ} \mathrm{C}(30 \mathrm{~s})$, amplification at $50^{\circ} \mathrm{C}(30 \mathrm{~s})$, and extension at $72^{\circ} \mathrm{C}(30 \mathrm{~s})$, followed by a final elongation at $72^{\circ} \mathrm{C}$ for $7 \mathrm{~min}$. Sequencing primers are outlined in Table 1.

\section{Nucleic acid diagnostics target sequencing}

Nucleotide sequence data used for real-time PCR NAD assay design and development was obtained either from publicly available databases or were generated in this study. Sequencing primers (Table 1) were designed to amplify the ssrA gene of Stenotrophomonas, and Serratia species. Amplification of the ssrA gene of $P$. aeruginosa and the $r n p B$ gene of Burkholderia species was performed as previously described [27]. Conventional PCR products were generated as described above, followed by purification using the High Pure PCR product purification kit (Roche Diagnostics). The purified PCR products were sequenced externally (Sequiserve, Vaterstetten, Germany).

\section{Internal Amplification Control for multiplex real-time PCR NAD assay}

The IAC used in this multiplex real-time diagnostics assay as previously described [27] was developed using a modified version of the composite primer approach 
Table 1 Oligonucleotide primers and probes used in this study

\begin{tabular}{|c|c|c|c|}
\hline Name & Function & Sequence $\left(5^{\prime}-3^{\prime}\right)$ & Target gene \\
\hline CIACF & Forward composite primer for IAC generation & TGAGGAAGACTTATTGGCTGATACCCAACTTGGAATG & Chimeric PCR product \\
\hline CIAC R & Reverse composite primer for IAC generation & CGGTACATTGTGGTCTTTAAGTCTTCACCAGAATAAAATTG & Chimeric PCR product \\
\hline Ser $F$ & Sequencing forward primer & GTGGAGCTGGGGGGAT & $s s r A$ \\
\hline Ser $R$ & Sequencing forward primer & GGGGCTGATTCTGGATTCG & $s s r A$ \\
\hline Psd F1 & Sequencing forward primer & GGATTTGAACCCCCGTCC & $s s r A$ \\
\hline Psd R2 & Sequencing reverse primer & AGGATTCGACGCCGGT & $s s r A$ \\
\hline BF1 & Sequencing forward primer & GAGGAAAGTCCGGACTCC & $r n p B$ \\
\hline BF2 & Sequencing forward primer & GGCAGGGTGATGGCTAA & $r n p B$ \\
\hline BR2 & Sequencing reverse primer & GATAAGCCGGATTCTGTGC & $r n p B$ \\
\hline Sten $\mathrm{F}$ & Sequencing forward primer & GGGGMYTACGGWTTCGAC & $s s r A$ \\
\hline Sten $\mathrm{R}$ & Sequencing forward primer & GGGARTCGAACCRSGTCC & $s s r A$ \\
\hline IAC F & IAC forward primer & TGAGGAAGACTTATTGGCTG & Chimeric PCR product \\
\hline IAC R & IAC reverse primer & CGGTACATTGTGGTCTITAAG & Chimeric PCR product \\
\hline IAC P & IAC specific hydrolysis probe & TYE665-TCCTTAGATGGTACCAGTGCCA- IBRQSp & Chimeric PCR product \\
\hline S. mar F & S. marcescens forward primer & GCACTACATGCTTAGTCCAAT & $s s r A$ \\
\hline S. mar R & S. marcescens reverse primer & CAGCTTAATACCCTGCTTAGAG & $s s r A$ \\
\hline S. mar P & S. marcescens specific hydrolysis probe & ROX-CACGCTACTGACAGACTAGCCT-BHQ2 & $s s r A$ \\
\hline BF1 & Burkholderia forward primer & GAGGAAAGTCCGGACTCC & $r n p B$ \\
\hline BR1 & Burkholderia reverse primer & TCTTACCGCACCGTTTCA & $r n p B$ \\
\hline Burk P & Burkholderia genus specific hydrolysis probe & FAM-ACACGCGGAACAGGGCAA-BHQ1 & $r n p B$ \\
\hline PF2 & P. aeruginosa forward primer & GACAGTCGTTTCGGGTTTAC & $s s r A$ \\
\hline PR1 & P. aeruginosa reverse primer & CGACGACAACTACGCTCT & $s s r A$ \\
\hline P. aer $P$ & P. aeruginosa specific hydrolysis probe & HEX-GCATCCCCTAGCGACTGCT-BHQ1 & $s s r A$ \\
\hline S. malt F & S. maltophilia forward primer & TACATGCTTAGCTCACCGT & $s s r A$ \\
\hline S. malt R & S. maltophilia reverse primer & CGAAACTGCTTGTGTCCAT & $s s r A$ \\
\hline S. malt P & S. maltophilia specific hydrolysis probe & CYAN500-CTGTTGTGTTCTAGTGCCGGAC-BHQ1 & ssrA \\
\hline
\end{tabular}

[37-39]. Briefly, the IAC amplifies and detects a chimeric PCR product containing nucleotide sequence of both Candida albicans ALS1 gene and the aqualysin 1 gene from Thermus aquaticus.

\section{Real-time PCR}

Real-time PCR NAD assays were initially tested in a monoplex format to determine the specificity and analytical sensitivity. Monoplex real-time PCR reactions were performed on the LightCycler 2.0 instrument using the LightCycler TaqMan Master kit (Roche Diagnostics). Each monoplex reaction contained $5 \mathrm{X}$ master mix $(4 \mu \mathrm{l})$, forward and reverse primer $(0.5 \mu \mathrm{M}$ final conc.), probe (0.2 $\mu \mathrm{M}$ final conc.), $0.5 \mathrm{U}$ uracil-DNA glycosylase (UDG,New England Biolabs), 5\% v/v Dimethyl sulphoxide (DMSO), template DNA $(2 \mu \mathrm{l})$ and the volume adjusted to $20 \mu \mathrm{l}$ with the addition of nuclease-free water. The thermal cycling parameters consisted of 10 min at $37^{\circ} \mathrm{C}$ to incubate UDG followed by $10 \mathrm{~min}$ incubation at $95^{\circ} \mathrm{C}$ to deactivate UDG, activate the polymerase and denature the template DNA. Subsequently, 50 cycles of $95^{\circ} \mathrm{C}$ for $10 \mathrm{~s}$ and $60^{\circ} \mathrm{C}$ for $30 \mathrm{~s}$ were performed, with a final a cooling step at $40^{\circ} \mathrm{C}$ for $10 \mathrm{~s}$. The temperature transition rate for all cycling steps was $20^{\circ} \mathrm{C} / \mathrm{s}$.

For multiplex real-time PCR the S. maltophilia, Burkholderia species and $P$. aeruginosa specific probes were labelled with Cyan 500, FAM, HEX and Black Hole Quencher 1 (BHQ1) respectively. The $S$. marcescens probe was labelled with ROX and Black Hole Quencher 2 (BHQ2). The IAC assay probe was labelled with TYE665 and Iowa Black ${ }^{\bullet}$ RQ-Sp (IBRQSp). The multiplex realtime PCR NAD assay was optimised to the required standards routinely used in this laboratory and the specificity and analytical sensitivity was determined.

Multiplex real-time PCR reactions were subsequently performed using the LightCycler 480 probes master kit (Roche Diagnostics) on the LightCycler 480 System I. Each multiplex reaction contained $2 \mathrm{X}$ master mix $(10 \mu \mathrm{l})$, forward and reverse primers $(0.5 \mu \mathrm{M}$ final 
conc.) CYAN500, FAM, HEX, ROX and TYE665 probes $(0.2 \mu \mathrm{M}$ final conc.), UDG (0.4 U), DMSO (5\% v/v). Template DNA $(5 \mu \mathrm{l})$ and IAC DNA $\left(1 \times 10^{4}\right.$ recombinant plasmid copies) were added to each reaction mix. Nucleasefree water was added to a final volume of $20 \mu \mathrm{l}$. A no template control reaction was included in each experiment. The cycling parameters used for multiplex reactions were in accordance with monoplex parameters (see previous paragraph). The temperature transition rate, referred to as the ramp rate on the LightCycler 480 , was $4.4^{\circ} \mathrm{C} / \mathrm{s}$ while heating and $2.2^{\circ} \mathrm{C} / \mathrm{s}$ on cooling. As outlined by the manufacturer [40] a colour compensation file was generated prior to experimental analysis to avoid fluorescence leakage between channels.

\section{Determining the specificity of the multiplex real-time diagnostic assay}

To demonstrate the specificity of the designed multiplex realtime PCR NAD assay, it was tested against genomic DNA isolated from a panel of 95 microorganisms (Additional file 1: Table S1) at a concentration of $10^{4}$ Genome Equivalents (GE) per reaction. Genome sizes were available from the NCBI website for all microorganisms of interest and were used to calculate the GE of each microorganism tested using previously published guidelines [41].

\section{Analytical sensitivity of the multiplex real-time diagnostic assay determined using probit regression analysis}

The analytical sensitivity of each assay in multiplex format was established by testing twelve replicates of eight bacterial genomic DNA concentrations, using probit regression analysis [42]. To determine the impact of genomic DNA from other microorganisms commonly associated with biocontaminated HPW distribution systems the LOD was also investigated in the presence of a background of pooled genomic DNA from 10 other bacteria commonly associated with water system contamination $[24,43,44]$. The final total concentration of the pooled bacterial genomic DNA was $10^{4} \mathrm{GE}$ per reaction. These bacteria were Klebsiella pneumonia DSM 9377, Ralstonia sp. DSM 13640, Enterobacter aerogenes NCTC 10006, Proteus mirabilis DSM 4479, Staphylococcus aureus DSM 21705, Acinetobacter baumannii DSM 30007, Bacillus cereus DSM 31 and 3 out of 4 of the following S. maltophilia DSM 50170, B. cepacia DSM 7288, P. aeruginosa DSM 19880 and S. marcescens DSM 30121 (genomic DNA from bacterial target subject to analytical sensitivity testing not included in background genomic DNA). The IAC, at a concentration of $10^{4}$ plasmid equivalents per reaction, was also included in all samples during sensitivity testing.

\section{Generation of external standard curves}

Three overnight microbial cultures of either S. maltophilia, Burkholderia species (for standard curve generation
B. cepacia DSM 7288 the type strain of the type species of the Burkholderia genus was used), P. aeruginosa or $S$. marcescens grown in R2A broth with an optical density at $600 \mathrm{~nm}\left(\mathrm{OD}_{600}\right)$ of 0.1 were serially diluted tenfold (6 dilutions) in sterile phosphate buffered saline (PBS) (Oxoid). One hundred $\mu \mathrm{l}$ of each dilution were spread on R2A agar and incubated for $48 \mathrm{~h}$ at $30^{\circ} \mathrm{C}$. These plates were used to count cfu. DNA was isolated from two hundred $\mu \mathrm{l}$ aliquots from each dilution (in triplicate) using the Quick-gDNA MiniPrep kit (Zymo Research) as per protocol outlined above. DNA was eluted in $50 \mu \mathrm{l}$ sterile nuclease free water which was then used as template DNA in the multiplex real time PCR reaction. Standard curves were derived by plotting threshold cycle $\left(C_{\mathrm{T}}\right)$ values against overnight plate counts $\left(\mathrm{CFU}\left(\log _{10}\right)\right)$.

\section{Sampling from HPW delivery system for microbiological analysis}

An Elix 35 HPW purification unit (Merck Millipore, Massachusetts, USA) and HPW delivery system based in a public building facility was investigated for bacterial contamination. The last full service of the Elix $35 \mathrm{HPW}$ purification unit was carried out approximately 36 months prior to first sampling. Sampling of HPW was performed at two point of use sources. Sampling point A was an outlet valve adjacent to the Elix $35 \mathrm{HPW}$ purification unit and point $B$ was a laboratory tap approximately $25-30 \mathrm{~m}$ from the Elix $35 \mathrm{HPW}$ purification unit. During the course of this study the Elix $35 \mathrm{HPW}$ purification unit had a new Progard TL1 System Cl2 Autoclean Pretreatment Pack and the Q-Gard TL Polishing Pack fitted. Samples of the HPW were subsequently taken from both points after this process was carried out. Before taking HPW samples, the outlets exteriors were cleaned with $70 \%$ ethanol, and HPW was subsequently allowed to flow for $2 \mathrm{~min}$ $(\sim 300 \mathrm{ml} / \mathrm{min})$. Five litre samples were collected into sterile containers and filtered using $0.45 \mu \mathrm{m}, 47 \mathrm{~mm}$ cellulose nitrate/acetate membrane filters (Millipore SAS, Molsheim Cedex, France) [45]. Each filter was placed in $1500 \mu \mathrm{l}$ Genomic Lysis Buffer (Quick-gDNA MiniPrep kit, Zymo Research) and incubated on rotating platform at room temperature for 5 - $10 \mathrm{~min}$ followed by steps 2 5 of the total DNA isolation from cell suspension procedure according to the manufacturer's guidelines. The DNA was eluted in $50 \mu \mathrm{l}$ sterile nuclease free water.

\section{Microbiological analysis of HPW delivery system}

(i) Conventional culture methods for the microbiological analysis of HPW delivery system.

Heterotrophic Plate Counts (HPCs) were performed by plating $100 \mu \mathrm{l}$ of HPW onto R2A agar and incubating at $37^{\circ} \mathrm{C}$ for $48 \mathrm{~h}$. Additionally, $100 \mu \mathrm{l}$ samples of HPW were plated on four selective agars. These were Pseudomonas agar, L-arabinose ornithine irgasan medium [46], 
B. cepacia medium, and B. cepacia specific agar (Fannin, Ireland). (Growth of S. maltophilia on B. cepacia medium was confirmed by culture of $S$. maltophilia strains (DSM $50170^{\mathrm{T}}$ and DSM 50173) at $30^{\circ} \mathrm{C}$ for $24 \mathrm{~h}$ ). Plates were incubated at $30^{\circ} \mathrm{C}$ for $48 \mathrm{~h}$. Single colonies were isolated and these microbial cultures were used to inoculate the BBL Crystal Enteric/Nonfermenter ID system panels (Becton Dickinson, New Jersey, USA), which were incubated at $37^{\circ} \mathrm{C}$ for $20 \mathrm{~h}$. Results were evaluated using BBL Crystal ID System Electronic Codebook.

(ii) Rapid NAD quantitative detection and identification of bacteria from a biocontaminated HPW delivery system.

Total genomic DNA isolated from filtered HPW samples was used as template DNA in the developed multiplex real-time PCR NAD assay to determine if the HPW samples were contaminated with S. maltophilia, Burkholderia species, $P$. aeruginosa or $S$. marcescens. In order to determine the degree of contamination of the HPW delivery system with these bacteria each positive result was absolutely quantified by comparison to one of the established external standard curves generated as described in section Generation of external standard curves.

\section{Results}

Diagnostics target identification and development

The NAD targets used in this study for the specific detection of the Burkholderia species and P. aeruginosa were previously described [27]. For the specific detection of the pathogens $S$. maltophilia and $S$. marcescens in silico analysis of a number of genes for use as a nucleic acid target was carried out (data not shown). The usefulness of these NAD target genes (ssrA, lepA, rnpB) has been previously demonstrated with the development of NAD assays to specifically detect microorganisms of interest [29-34,47]. The analysis of the $s s r A$ gene revealed significant intragenic nucleotide sequence variation between closely related species within the nucleotide gene sequences of $S$. maltophilia and $S$. marcescens to allow for the design of species specific probes for both these microorganisms of interest. A BLAST analysis of each target probe did not show any cross reactivity between specific probes and any other non target species/strains (data not shown).

\section{Specificity of the multiplex real-time diagnostic assay}

The specificity of each real-time PCR NAD assay was confirmed both in monoplex and multiplex formats using the panel of microorganisms listed in Additional file 1: Table S1. The S. maltophilia and S. marcescens specific real-time PCR NAD assays each detected five positive control strains and did not detect any of the remaining 90 microorganisms tested in this study. The $P$. aeruginosa specific real-time PCR NAD assay detected the 14
P. aeruginosa strains in our collection. The remaining 81 microorganisms tested were not detected. Ten Burkholderia species were tested using the Burkholderia genus specific real-time PCR NAD assay. All 10 Burkholderia species were detected and none of the remaining 85 microorganisms tested were detected. The specificity of the IAC assay was also tested using the same panel of microorganisms and no cross reactivity was observed. For complete results of specificity testing see Table 2 .

\section{Analytical sensitivity testing of the multiplex real-time PCR NAD assay}

The LOD of each diagnostics assay was evaluated in both monoplex and multiplex real-time PCR formats. Total genomic or plasmid DNA was quantified and serial dilutions were prepared from $10^{5}$ to 0.1 genome/plasmid equivalents. The dilution series was run in triplicate for each monoplex real-time PCR NAD assay. In a monoplex format, all five diagnostics assays had an analytical sensitivity of less than $10 \mathrm{GE}$. The LOD of the real-time multiplex diagnostics assay was established using probit regression analysis with 12 replicates for each dilution. With 95\% confidence, the analytical sensitivities of the $S$. maltophilia, B. cepacia, $P$. aeruginosa and the S. marcescens assays are 8.5 GE, 5.7 GE, 3.2 GE and 7.4 GE respectively. The LOD for each assay when investigated in the presence of a background of pooled genomic DNA from 10 other microorganisms at a concentration of $10^{4} \mathrm{GE}$ per reaction are 9.5 GE, 6.5 GE, 3.3 GE and 7.7 GE respectively. The IAC, at a concentration of $10^{4}$ plasmid equivalents per reaction, was included in all samples during sensitivity testing and was detected at $C_{T}$ values from 27.2 - 28.6. The amplification efficiency (E) of the multiplex real-time PCR reactions ranged from $94-102 \%$.

\section{Limit of quantification (LOQ)}

DNA extracted from different concentrations of overnight culture was used as template DNA in the multiplex realtime PCR reaction. Standard curves were derived by plotting threshold cycle $\left(C_{\mathrm{T}}\right)$ values against overnight plate counts (CFU $\left.\left(\log _{10}\right)\right)$. The dynamic range of each assay was established and the limit of quantification for each assay was determined. The LOQ of the S. maltophilia, B.

Table 2 Microbial specificity testing of the developed multiplex assay

\begin{tabular}{llll}
\hline Assay & $\begin{array}{l}\text { Diagnostics } \\
\text { gene target }\end{array}$ & $\begin{array}{l}\text { Inclusivity } \\
\text { testing }\end{array}$ & $\begin{array}{l}\text { Exclusivity } \\
\text { testing }\end{array}$ \\
\hline S. maltophilia & ssrA & $5 / 5$ & $0 / 90$ \\
Burkholderia genus & rnpB & $10 / 10$ & $0 / 85$ \\
P. aeruginosa & SSrA & $14 / 14$ & $0 / 81$ \\
S. marcescens & SSrA & $5 / 5$ & $0 / 90$ \\
\hline
\end{tabular}


cepacia, $P$. aeruginosa and the $S$. marcescens assays are $88.5 \mathrm{cfu}, 59.7 \mathrm{cfu}, 73.2 \mathrm{cfu}$ and $87.4 \mathrm{cfu}$ respectively.

\section{Microbiological analysis of a HPW delivery system}

(i) Conventional culture methods for the microbial analysis of a HPW delivery system.

HPW samples were cultured on R2A agar to determine HPCs. HPCs observed in the HPW delivery system ranged from $2.93 \times 10^{6}-3.67 \times 10^{6} / \mathrm{L}$ (Additional file 1: Table S2). This demonstrates naturally occurring high bacterial contamination in the HPW delivery system. A biochemical analysis of microbial colonies isolated on R2A agar and selective agar was performed using the BBL crystal enteric NF system. This analysis confirmed the presence of both $S$. maltophilia and Burkholderia species in the HPW delivery system. However, neither $P$. aeruginosa nor $S$. marcescens were detected using this analysis. Other bacteria identified in the HPW delivery system using the BBL crystal enteric NF system were Sphingomonas sp., Flavinonas sp and Vibrio sp. The Turn Around Time (TAT) to result for the microbiological analysis of the HPW delivery system using conventional microbial culture methods was $>72 \mathrm{~h}$.

(ii) Rapid NAD quantitative detection and identification of bacteria in a HPW delivery system.

The dynamic range for the external standard curves used in this study for the absolute quantification of pathogenic bacteria present in HPW delivery system was $10^{2}-10^{7} \mathrm{cfu}$. For the quantitative detection and identification of bacteria in the HPW delivery system total genomic DNA was extracted from each filter and used as a template in the multiplex real-time PCR NAD assay developed in this study. The results were absolutely quantified by comparison to the external standards curves (see section Generation of external standard curves). From this analysis, it was determined that the HPW delivery system was contaminated with both S. maltophilia and Burkholderia species. The concentration of S. maltophilia detected in the HPW ranged from $5.75 \times 10^{1}$ $7.65 \times 10^{1} \mathrm{cfu} / 100 \mathrm{ml}$ at sampling point $\mathrm{A}$ and $1.30 \times$ $10^{2}-1.72 \times 10^{2} \mathrm{cfu} / 100 \mathrm{ml}$ at sampling point $\mathrm{B}$. The concentration of Burkholderia species observed in the HPW was higher with concentrations of $4.06 \times 10^{2}$ $7.42 \times 10^{2} \mathrm{cfu} / 100 \mathrm{ml}$ at sampling point $\mathrm{A}$ and $6.88 \times$ $10^{2}-1.17 \times 10^{3} \mathrm{cfu} / 100 \mathrm{ml}$ at sampling point B. P. aeruginosa and $S$. marcescens were not detected. Both European and US guidelines for microbial analysis of HPW recommend that under normal conditions an appropriate action level is a microbial count of $10 \mathrm{cfu} /$ $100 \mathrm{ml}[48,49]$. The concentration of both S. maltophilia and Burkholderia species detected in the HPW distribution system tested was above the recommended action level. For complete results of this analysis see Table 3. The TAT to result for the microbiological analysis of the HPW delivery system using the multiplex real-time PCR NAD assay was $<5 \mathrm{~h}$.

\section{Discussion}

The use of rapid quantitative multiplex real-time PCR NAD assays for the analysis of microbial contamination in water and HPW distribution systems can potentially overcome some of the limitations that are associated with conventional culture based microbiological diagnostics techniques traditionally used to monitor water quality. Conventional microbial analysis of water and HPW distribution systems by traditional culture techniques are labour-intensive and can take between $2-7$ days, which can result in significant delays in identifying the contaminating microorganism [50]. Furthermore, conventional microbial culture methodologies traditionally used to analyse the biocontamination of water and HPW distribution systems assess the number of bacteria

Table 3 Microbiological analysis of a HPW delivery system using developed methodology

\begin{tabular}{|c|c|c|c|c|c|c|}
\hline \multirow[t]{2}{*}{$\begin{array}{l}\text { Sampling } \\
\text { point }\end{array}$} & \multirow[t]{2}{*}{$\begin{array}{l}\text { Sampling } \\
\text { time }\end{array}$} & \multirow{2}{*}{$\begin{array}{l}\mathrm{C}_{\mathrm{T}} \text { value (SD) } \\
\text { S. maltophilia }\end{array}$} & \multirow{2}{*}{$\begin{array}{l}{ }^{a} \text { Mean calculated } \\
\text { cfu/100 ml (SD) } \\
\text { S. maltophilia }\end{array}$} & \multirow{2}{*}{$\begin{array}{l}\mathrm{C}_{\mathrm{T}} \text { value }(\mathrm{SD}) \\
\text { Burkholderia }\end{array}$} & \multirow{2}{*}{$\begin{array}{l}{ }^{\text {a }} \text { Mean calculated } \\
\text { cfu/100 ml (SD) } \\
\text { Burkholderia }\end{array}$} & \multirow{2}{*}{$\begin{array}{l}\text { Above threshold } \\
\text { EU/US guidelines } \\
\text { action level of }> \\
10 \mathrm{cfu} / 100 \mathrm{ml}\end{array}$} \\
\hline & & & & & & \\
\hline $\bar{A}$ & 1 & $29.02(0.07)$ & $7.7 \times 10^{1}(37)$ & $27.14(0.15)$ & $7.4 \times 10^{2}(145)$ & Yes \\
\hline$A$ & 2 & $29.25(0.21)$ & $6.5 \times 10^{1}(103)$ & $27.81(0.23)$ & $6.2 \times 10^{2}(97)$ & Yes \\
\hline$A$ & 3 & $29.40(0.04)$ & $5.8 \times 10^{1}(13)$ & $28.47(0.22)$ & $4.1 \times 10^{2}(560)$ & Yes \\
\hline B & 1 & $27.90(0.14)$ & $1.7 \times 10^{2}(162)$ & $27.64(0.07)$ & $6.9 \times 10^{2}(333)$ & Yes \\
\hline B & 2 & $28.30(0.27)$ & $1.3 \times 10^{2}(246)$ & $27.16(0.03)$ & $9.4 \times 10^{2}(167)$ & Yes \\
\hline B & 3 & $28.10(0.12)$ & $1.5 \times 10^{2}(139)$ & $26.83(0.16)$ & $1.2 \times 10^{3}(867)$ & Yes \\
\hline
\end{tabular}

$\mathrm{C}_{\mathrm{T}}$ Threshold cycle.

${ }^{a}$ Mean calculated cfu/100 $\mathrm{ml}$ calculated by multiplex real time PCR.

A Valve adjacent to Elix $35 \mathrm{HPW}$ purification system.

B Laboratory tap approximately 25 - 30 m from the Elix 35 HPW purification system.

${ }^{1}$ Before Pretreatment and Polishing Pack change.

${ }^{2}$ one day post Pretreatment and Polishing Pack change.

${ }^{3}$ one week post Pretreatment and Polishing Pack change. 
that can form visible colonies on a solid medium under specific test growth conditions (e.g. incubation temperature, culture medium and incubation time). However, these approaches only reveal the presence of bacteria culturable under these conditions and may not grow all the contaminating microorganisms present [51]. Therefore, monitoring water quality by HPCs enumeration with conventional microbial culture methods may only represent a relatively small proportion of the total viable microbial population in a biocontaminated water or HPW distribution system [25].

It is possible that the use of NAD technologies such as real-time PCR for the analysis of microbial contamination in water and HPW distribution systems could result in the detection of DNA from dead microorganisms. This may result in an overestimation of the microbial contamination or the risk of false positive results. However, the presence of any DNA from pathogenic microorganisms in a water sample indicates that there is biological contamination within the system. Any contamination with pathogenic microorganisms within water distribution systems even if present at low concentrations should be considered a risk.

In a healthcare setting, if the water or HPW distribution system is suspected as a potential source of HCAIs, the ability to specifically detect and identify pathogenic microorganisms rapidly would allow the required infection control and prevention measures to be taken promptly. A delay in this analysis could result in an increased risk of patients contracting HCAIs and subsequently a significant increase in both the duration and cost of a healthcare stay. In this setting, where there is an increasing proportion of immunologically compromised patients there is added potential for infection by pathogenic microorganisms originating from biocontaminated water and HPW distribution systems. A recent commentary on waterborne pathogen detection [52] highlights that although hospital water and HPW distribution systems have been implicated in the spread of HCAIs there is a lack of evidence of direct transmission from water distribution systems. However, it concludes that a microbiological investigation of the hospital water distribution system, such as that performed by Cristina et al. [6], may be beneficial in identifying the position, frequency and extent of contamination. Such analysis could then be used to assess the degree of risk to patients. Therefore an ability to specifically detect and identify pathogenic microorganisms in the HPW distribution system rapidly may aid in determining the potential source and causative agent of the HCAIs, thereby allowing the required infection control and prevention measures to be taken promptly.

In this current study the internally controlled novel multiplex real-time PCR diagnostics assay developed uses
NAD targets for the rapid specific quantitative detection and identification of four important human pathogenic bacteria associated with the contamination of HPW distribution systems $[24,43,53]$. The developed multiplex realtime PCR NAD assay was determined to be $100 \%$ specific when tested against a panel of 95 microorganisms with no cross reactivity observed (Table 2 and Additional file 1: Table S1). To our knowledge, this is the first report of an internally controlled 5-plex assay for the quantitative detection and identification of S. maltophilia, Burkholderia species, $P$. aeruginosa and $S$. marcescens for use in the microbial analysis of a HPW distribution system.

The analytical sensitivity of all four diagnostics assays described in this study is less than $10 \mathrm{GE}$ allowing for the potential detection of low levels of pathogenic bacteria present in a biocontaminated HPW distribution system. The 5-plex PCR NAD assay described does not require microbial culture pre-enrichment of the HPW sample to increase analytical sensitivity prior to running the diagnostics assay. This ability to detect contaminating microorganisms without microbial culture pre-enrichment is a significant advantage, as the inclusion of a microbial culture pre-enrichment step eliminates the ability to absolutely quantify the contaminating microorganism in the HPW. This is important as routine testing of HPW needs to be both qualitative and quantitative [48]. Another major advantage of not including a pre-incubation step is that the assay TAT is significantly reduced. Using the developed multiplex real-time PCR NAD assay, the TAT to result inclusive of HPW sampling and filtration, DNA preparation, real-time PCR reaction, and data analysis is $<$ $5 \mathrm{~h}$ in contrast to 2-7 days using traditional microbial culture diagnostics methodologies [49].

A HPW delivery system supplied by an Elix 35 HPW purification unit was evaluated for microbiological contamination using both traditional microbial culture methodologies and the developed NAD assay and associated methodology. This analysis was performed both before and after a pretreatment and polishing pack change of the Millipore Elix $35 \mathrm{HPW}$ purification unit. The developed multiplex real-time PCR NAD assay determined that the HPW delivery system was contaminated with the opportunistic human pathogens S. maltophilia and Burkholderia species. The numbers of both of these GNB-NE present in the HPW distribution system was above the action level threshold of $10 \mathrm{cfu} / 100 \mathrm{ml} \mathrm{rec}-$ ommended by both European and US guidelines $[48,49]$. The presence of both S. maltophilia and Burkholderia species in the HPW delivery system was also confirmed by traditional microbial culture methods using the BBL crystal enteric NF system (Becton Dickinson). Neither $P$. aeruginosa nor $S$. marcescens was detected in the HPW using the developed NAD test or by traditional microbial culture methods. 
This current study, which was designed in accordance with MIQE guidelines [28], has focused on the development of a rapid methodology for the absolute quantification, detection and identification of four pathogenic bacteria from an operating HPW distribution system. Other studies have demonstrated that biocontamination of water and HPW distribution systems can occur with a number of other important human pathogenic microorganisms which were not investigated in this study $[24,43,54]$. We propose that with the inclusion of additional NAD tests, this methodology could be used to detect and identify a more comprehensive panel of pathogenic microorganisms (bacterial and fungal) for use in the analysis of microbial contaminants of water and HPW distribution systems. While the developed rapid culture independent methodology was demonstrated using a limited number of samples from a HPW distribution system the same methodology could be applied to other water and HPW distribution systems such as those in a clinical setting. We intend to evaluate a number of other water and HPW distribution systems over a longer period to further demonstrate the robustness of the developed methodology.

\section{Conclusion}

As water and HPW is routinely used for a wide range of applications in the clinical and industrial sectors, it is essential that water purification units and water distribution systems are subject to strict maintenance schedules and stringent microbiological analysis. The rapid culture independent methodology described here may be a valuable diagnostics tool and have many useful applications in both these sectors.

\section{Additional file}

Additional file 1: Table S1. Bacterial and fungal species and strains used in this study. Table S2. TVC from microbiological analysis of HPW delivery system by conventional culture methodologies.

\section{Abbreviations \\ HPW: High purity water; NAD: Nucleic acid diagnostics; PCR: Polymerase chain reaction; TAT: Turnaround time; HCAls: Healthcare Associated Infections; GE: Genome equivalents; CFU: Colony forming units; TVC: Total viable counts; LOD: Limit of detection; HPCs: Heterotrophic Plate Counts (HPCS).}

\section{Competing interests}

The authors declare that they have no competing interests.

\section{Authors' contributions}

EM performed all laboratory experiments, analysed the data and wrote the manuscript. TB directed the study, contributed to writing of the manuscript and is the corresponding author. KR, NT and CS contributed to certain aspects of the direction of the study and they also contributed to the editing and revision of the manuscript. All authors read and approved the final manuscript.

\section{Acknowledgements}

We wish to acknowledge the College of Science and the Thomas Crawford Hayes Fund, National University of Ireland, Galway who have supported EM with a postgraduate scholarship. This publication, in part, has also emanated from research conducted with the financial support of Science Foundation Ireland under Grant SFI 13/TIDA/I2597. The authors also wish to acknowledge the European Union's Seventh Programme for research.

\section{Author details}

${ }^{1}$ Nucleic Acid Diagnostics Research Laboratory (NADRL), Microbiology, School of Natural Sciences, National University of Ireland Galway, Galway, Ireland.

${ }^{2}$ Marine Microbial Ecology Laboratory, Microbiology, School of Natural

Sciences, National University of Ireland Galway, Galway, Ireland.

Received: 7 November 2014 Accepted: 6 February 2015

Published online: 18 February 2015

\section{References}

1. Guo J-H, Skinner GW, Harcum WW, Barnum PE. Pharmaceutical applications of naturally occurring water-soluble polymers. Pharmaceutical Sci Tech Today. 1998; (6):254-61.

2. Poretti M. Quality control of water as raw material in the food industry. Food Control. 1990;1 (2):79-83.

3. Meltzer TH: High-purity water preparation for the semiconductor, pharmaceutical, and power industries: Tall Oaks Publishing

4. Walker JT, Marsh PD. A review of biofilms and their role in microbial contamination of dental unit water systems (DUWS). Int Biodeter Biodegr. 2004;54(2-3):87-98.

5. Walker J: Decontamination in Hospitals and Healthcare: Woodhead Publishing; 2014

6. Cristina MLBP, Spagnolo AMBP, Casini BBMS, Baggiani AMD, Giudice PDMD, Brusaferro SMD, et al. The impact of aerators on water contamination by emerging gram-negative opportunists in at-risk hospital departments. Infect Control Hosp Epidemiol. 2014;35(2):122-9.

7. Anaissie EJ, Penzak SR, Dignani MC. The hospital water supply as a source of nosocomial infections: a plea for action. Arch Intern Med. 2002;162(13):1483-92.

8. Bert F, Maubec E, Bruneau B, Berry P, Lambert-Zechovsky N. Multi-resistant Pseudomonas aeruginosa outbreak associated with contaminated tap water in a neurosurgery intensive care unit. J Hosp Infect. 1998;39(1):53-62.

9. Roberts LA, Collignon PJ, Cramp VB, Alexander S, McFarlane AE, Graham E, et al. An Australia-wide epidemic of Pseudomonas pickettii bacteraemia due to contaminated "sterile" water for injection. Med J Aust. 1990;152(12):652-5.

10. Moreira BM, Leobons MBGP, Pellegrino FLPC, Santos M, Teixeira LM, de Andrade ME, et al. Ralstonia pickettii and Burkholderia cepacia complex bloodstream infections related to infusion of contaminated water for injection. J Hosp Infect. 2005;60(1):51-5.

11. Loveday HP, Wilson JA, Kerr K, Pitchers R, Walker JT, Browne J. Association between healthcare water systems and Pseudomonas aeruginosa infections: a rapid systematic review. J Hosp Infect. 2014;86(1):7-15.

12. Walker JT, Jhutty A, Parks S, Willis C, Copley V, Turton JF, et al. Investigation of healthcare-acquired infections associated with Pseudomonas aeruginosa biofilms in taps in neonatal units in Northern Ireland. J Hosp Infect. 2014;86(1):16-23.

13. Verweij PE, Meis JFGM, Christmann V, Van Der Bor M, Melchers WJG, Hilderink BGM, et al. Nosocomial outbreak of colonization and infection with Stenotrophomonas maltophilia in preterm infants associated with contaminated tap water. Epidemiology Infect. 1998;120(03):251-6.

14. Lai KK, Brown BA, Westerling JA, Fontecchio SA, Zhang Y, Wallace RJ. Long-Term Laboratory Contamination by Mycobacterium abscessus Resulting in Two Pseudo-Outbreaks: Recognition with Use of Random Amplified Polymorphic DNA (RAPD) Polymerase Chain Reaction. Clin Infect Dis. 1998:27(1):169-75.

15. El Sahly HM, Septimus E, Soini H, Septimus J, Wallace RJ, Pan X, et al. Mycobacterium simiae pseudo-outbreak resulting from a contaminated hospital water supply in Houston. Texas Clin Infect Dis. 2002;35(7):802-7.

16. Verschraegen G, Claeys G, Meeus G, Delanghe M. Pseudomonas pickettii as a cause of pseudobacteremia. J Clin Microbiol. 1985;21 (2):278-9.

17. Heard S, Lawrence S, Holmes B, Costas M. A pseudo-outbreak of Pseudomonas on a special care baby unit. J Hosp Infect. 1990;16(1):59-65. 
18. Forman W, Axelrod P, St John K, Kostman J, Khater C, Woodwell J, et al. Investigation of a pseudo-outbreak of orthopedic infections caused by Pseudomonas aeruginosa. Infect Control Hosp Epidemiology Official J Society Hosp Epidemiologists America. 1994;15(10):652-7.

19. Farmer JJ, Davis BR, Hickman FW, Presley DB, Bodey GP, Negut M, et al. Detection of Serratia outbreaks in hospital. Lancet. 1976;2(7983):455-9.

20. Wiemer KE, Anderson A, Stewart B. The importance of water quality for media preparation. Hum Reprod. 1998;13 suppl 4:166-72

21. Tothill I, Seal K. Biodeterioration of waterborne paint cellulose thickeners. Int Biodeter Biodegr. 1993:31(4):241-54.

22. Jimenez L, Ignar R, Smalls S, Grech P, Hamilton J, Bosko Y, et al. Molecular detection of bacterial indicators in cosmetic/pharmaceuticals and raw materials. J Ind Microbiol Biotechnol. 1999;22(2):93-5.

23. Byrd JJ, Xu HS, Colwell RR. Viable but nonculturable bacteria in drinking water. Appl Environ Microbiol. 1991;57(3):875-8.

24. Kulakov LA, McAlister MB, Ogden KL, Larkin MJ, O'Hanlon JF. Analysis of bacteria contaminating ultrapure water in industrial systems. Appl Environ Microbiol. 2002;68(4):1548-55.

25. Colwell RR, Brayton PR, Grimes DJ, Roszak DB, Huq SA, Palmer LM. Viable but Non-Culturable Vibrio cholerae and Related Pathogens in the Environment: Implications for Release of Genetically Engineered Microorganisms. Nat Biotech. 1985;3(9):817-20.

26. Mittelman M, Geesey GG: Biological fouling of industrial water systems: a problem solving approach: Water Micro Assoc; 1987

27. Minogue E, Reddington K, Dorai-Raj S, Tuite N, Clancy E, Barry T. Diagnostics method for the rapid quantitative detection and identification of low-level contamination of high-purity water with pathogenic bacteria. J Ind Microbiol Biotechnol. 2013;40(9):1005-13.

28. Bustin SA, Benes V, Garson JA, Hellemans J, Huggett J, Kubista M, et al. The MIQE guidelines: minimum information for publication of quantitative real-time PCR experiments. Clin Chem. 2009:55(4):611-22.

29. Gopalan V, Vioque A, Altman S. RNase P: variations and uses. J Bio Chem 2002:277(9):6759-62.

30. Innings Å, Ullberg M, Johansson A, Rubin CJ, Noreus N, Isaksson M, et al. Multiplex real-time PCR targeting the RNase P RNA gene for detection and identification of Candida species in blood. J Clin Microbiol. 2007:45(3):874-80.

31. Clancy E, Glynn B, Reddington K, Smith T, Barry T. Culture confirmation of Listeria monocytogenes using tmRNA as a diagnostics target. J Microbiol Methods. 2012;88(3):427-9.

32. Reddington $K$, Zumla A, Bates M, van Soolingen D, Niemann S, Barry T, et al. SeekTB, a two-stage multiplex real-time-PCR-based method for differentiation of the mycobacterium tuberculosis complex. J Clin Microbiol. 2012;50(7):2203-6

33. O'Grady J, Lacey K, Glynn B, Smith TJ, Barry T, Maher M. tmRNA - a novel highcopy-number RNA diagnostic target - its application for Staphylococcus aureus detection using real-time NASBA. FEMS Microbiol Lett. 2009;301(2):218--223.

34. Wernecke M, Mullen C, Sharma V, Morrison J, Barry T, Maher M, et al. Evaluation of a novel real-time PCR test based on the ssrA gene for the identification of group B streptococci in vaginal swabs. BMC Infectious Diseases. 2009;9(1):148

35. Barry T, Colleran G, Glennon M, Dunican L, Gannon F. The 16s/23s ribosomal spacer region as a target for DNA probes to identify eubacteria. Genome Res. 1991;1(1):51-6.

36. Robertson JM, Walsh-Weller J. An introduction to PCR primer design and optimization of amplification reactions. Methods Mol Biol. 1998:98:121-54.

37. Hoorfar J, Ahrens P, Radstrom P. Automated 5' Nuclease PCR Assay for Identification of Salmonella enterica. J Clin Microbiol. 2000;38(9):3429-35.

38. Hoorfar J, Malorny B, Abdulmawjood A, Cook N, Wagner M, Fach P. Practical considerations in design of internal amplification controls for diagnostic PCR assays. J Clin Microbiol. 2004;42(5):1863-8.

39. O' Grady J, Sedano-Balbás S, Maher M, Smith T, Barry T. Rapid real-time PCR detection of Listeria monocytogenes in enriched food samples based on the ssrA gene, a novel diagnostic target. Food Microbiol. 2008;25(1):75-84.

40. Anon: LightCycler ${ }^{\circledast} 480$ User guide. In: Roche LightCycler ${ }^{\oplus} 480$ Instrument Operator's Manual 2008: 248-256

41. Yun JJ, Heisler LE, Hwang IIL, Wilkins O, Lau SK, Hyrcza M, et al. Genomic DNA functions as a universal external standard in quantitative real-time PCR. Nucleic Acids Res. 2006;34(12):e85

42. Motulsky H: Fitting Models to Biological Data Using Linear and Nonlinear Regression: A Practical Guide to Curve Fitting: Oxford University Press; 2004
43. Bohus V, Tóth EM, Székely AJ, Makk J, Baranyi K, Patek G, et al. Microbiological investigation of an industrial ultra pure supply water plant using cultivation-based and cultivation-independent methods. Water Res. 2010:44(20):6124-32.

44. Penna VT, Martins SA, Mazzola PG. Identification of bacteria in drinking and purified water during the monitoring of a typical water purification system. BMC Public Health. 2002;2:13.

45. Anon: British Pharmacopoeia Volume I \& 2. In: Medicinal and Pharmaceutical Substances: Water for Injection Ph Eur monograph 1927. London, United Kingdom: British Pharmacopoeia Commission 2012

46. Gibson S, Friedman H. L-Arabinose-ornithine-Irgasan medium for differentiating Serratia species. J Clin Microbiol. 1978;7(3):279-81.

47. McGuinness S, McCabe E, O'Regan E, Dolan A, Duffy G, Burgess C, et al Development and validation of a rapid real-time PCR based method for the specific detection of Salmonella on fresh meat. Meat Sci. 2009;83(3):555-62.

48. Anon: European Directorate for the Quality of Medicines. In: Purified water. vol. European Pharmacopoeia 6.3. Strasbourg, France: EDQM Council of Europe; 2009: pp 4344-4346.

49. Anon: U.S Pharmacopeia. In: Water for Pharmaceutical Purposes General Chapter 1231. Maryland, USA: United States Pharmacopeial Convention; 2011.

50. Sartory DP, Watkins J. Conventional culture for water quality assessment: is there a future? J Appl Microbiol. 1998:85(S1):225S-33.

51. Reasoner DJ, Geldreich EE. A new medium for the enumeration and subculture of bacteria from potable water. Appl Environ Microbiol. 1985:49(1):1-7.

52. Decker BKMD, Palmore TNMD. Commentary: waterborne pathogen detection: more than just "location, location, location". Infect Control Hosp Epidemiol. 2014;35(2):130-1.

53. Favero MS, Carson LA, Bond WW, Petersen NJ. Pseudomonas aeruginosa: growth in distilled water from hospitals. Science. 1971;173(3999):836-8.

54. Baba T, Matsumoto R, Yamaguchi N, Nasu M. Bacterial population dynamics in a reverse-osmosis water purification system determined by fluorescent staining and PCR-denaturing gradient Gel electrophoresis. Microbes Environ. 2009:24(2):163-7.

\section{Submit your next manuscript to BioMed Central and take full advantage of:}

- Convenient online submission

- Thorough peer review

- No space constraints or color figure charges

- Immediate publication on acceptance

- Inclusion in PubMed, CAS, Scopus and Google Scholar

- Research which is freely available for redistribution 